\title{
Zirkonyum Oksit Altyapı ve Veneer Seramik Bağlantı Mekanizması ve Bağlantıyı Etkileyen Faktörler
}

\author{
Connection Mechanism Between Zirconium Oxide cores and Veneer Ceramic and the factors \\ Affecting Connection
}

Merve YIILDİRAK ${ }^{1}$, Sebnem Begum TURKER²@, Yasemin OZKAN ${ }^{\circledR 0}$

Öz

Artan estetik beklentiler sonucunda sabit protetik tedavi yapımında tam seramik restorasyonlar kullanılmaktadır. Zirkonyum oksit ile güçlendirilmiş seramikler gelişmiş estetik ve mekanik özelliklere, biyouyumluluğa, düşük plak birikimine ve düşük termal iletkenliğe sahiptirler. Zirkonya altyapılı restorasyonların geleneksel metal altyap1lı restorasyonlara alternatif bir tedavi olduğu düşünülmektedir. Ancak yapısındaki yüksek kristalin faz nedeniyle opak bir yapıya sahip olduğu bilinmektedir. Estetik gereksinimler zirkonyanın monolitik kullanımını sınırlandırarak, optimum renk ve translüsensiye sahip bir veneer seramiği ile kaplanmasını gerektirmektedir. Zirkonya alt yap1 ve veneer seramiği arasındaki bağlantı; altyapıya uygulanan yüzey işlemleri, veneer seramiğine uygulanma yöntemi ve mekanik özellikleri gibi faktörlerden etkilenmektedir. Bağlantıyı etkileyen faktörler bilinmesine rağmen bağlantı mekanizması bilinmemektedir. $\mathrm{Bu}$ derleme; zirkonya ve veneer seramikler arasındaki bağlantı mekanizmasını ve etkileyen faktörler ile ilgili genel bilgi veren bir literatür taramasıdır.

Anahtar Kelimeler:zirkonya altyap1, zirkonya - veneer bağlantısı.

\begin{abstract}
All-ceramic restorations are preferred in fixed prosthodontics treatments as a result of increasing esthetic expectations. Zirconium-oxide based ceramics offer advanced esthetic and mechanical features, bio-compatibility, decreased plaque accumulation and low thermal conductivity. Zirconia-based restorations are considered to be an alternative treatment method
\end{abstract}

\footnotetext{
Merve Yildirak (可)

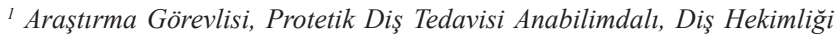
Fakültesi, Marmara Üniversitesi, Istanbul, Türkiye.

Telefon Numarası: +902164211621 Fax Numarasi: +902164210291

e-mail:merve.karagoz@marmara.edu.tr

Sebnem Begum Turker

${ }^{2}$ Profesör, Protetik Diş Tedavisi Anabilimdalı, Diş Hekimliği Fakültesi, Marmara Üniversitesi, İstanbul, Türkiye.

Yasemin Ozkan

${ }^{3}$ Profesör, Protetik Diş Tedavisi Anabilimdall, Diş Hekimliği Fakültesi, Marmara Üniversitesi, İstanbul, Türkiye.
}

Submitted / Gönderilme: 13.09.2018

Accepted/Kabul: 14.05.2019 to conventional metal ceramic restorations. However it is known that zirconia based ceramic has increased opacity due to its high crystalline content. Esthetic expectations limited the monolitic usage of zirconia and require veneering with a ceramic which has optimal colour and transluceny. The bond strength between zirconia and veneering ceramic is affected by the factors like surface treatments applied on zirconia cores, the mechanical properties of veneer ceramics and the application methods of ceramics. But the bonding mechanism between zirconia and veneering ceramic is still unknown. This article offers a review of the literature about the factors affecting the bond strength between zirconia cores and veneer ceramics ceramics and their bonding mechanism.

Keywords: Zirconia infrastructure, zirconia-veneer connection

\section{Giriș}

Zirkonyum, diş hekimliğinde 1990'ların başında kullanılmaya başlanmıştır. Başlangıçta endodontik postlarda, implantların üst yapılarında ve ortodontik braketlerde kullanılırken, son zamanlarda tam seramik restorasyonlarda alternatif bir altyapı materyali olmuştur (Raigrodski ve arkadaşları, 2004).

Zirkonyum ile güçlendirilen seramiklerden Y-TZP (yitrium-oxide-partially-stabilized zirconium), diş hekimliğinde en çok kullanılan şeklidir. Yaklaşık \%3 veya $\% 5$ yitrium oksit ile zirkonyumun kısmen stabile edilmesiyle elde edilmiştir (Blatz ve arkadaşları, 2004).

Zirkonyum oda sicaklığında tetragonal fazda stabil, monoklinik fazda metastabildir, yani maddenin içinde onu monoklinik faza döndürmeye çalışan enerji kalmıştır. (Kelly, 2004). Bu dönüşüm geri dönüşümlüdür. Aşındırma, kumlama ve 1sıl yaşlandırma gibi yüksek lokal stresler altında dönüşüm gerçekleşebilir ve \%3-5 arasında lokal hacim artışı oluşur. Oluşan hacim artışı ile meydana gelen baskı stresleri dış kuvvetleri nötralize ederek materyal içindeki mikroçatlakların ilerlemesine engel olur. $\mathrm{Bu}$ 
mekanizmaya 'dönüşüm doygunluğu' (phase transformation toughening) denir (Silva ve arkadaşları, 2010). Dönüşüm doygunluğu materyalin bir çatlak varlığında gelen yüklere karşı koyabilme kapasitesi olarak da tanımlamıştır (Lughi ve Sergo, 2010). Ancak bu dönüşüm kontrol altına alınmalıdır, çünkü hacim artışı ileri derecede kırıklara sebep olabilir. Bunu önlemek amaciyla saf zirkonyaya yitrium oksit eklenmiş ve zirkonyumun sinterleme sonrası oda sıcaklığında tetragonal fazda stabil kalması sağlanmıştır (Kelly, 2004).

Zirkonyanın tetragonal fazının termal genleşme katsayısı $6.5^{-6} \mathrm{C}$ iken, kübik fazının termal genleşme katsayısı $10.5^{-6}$ C'dir. Bu iki faz arasındaki termal genleşme katsayısı farkı; yap1 içerisinde mikroçatlakların oluşmasına neden olur. Oluşan mikroçatlaklar iç basınç meydana getirerek ileride oluşacak daha büyük çatlakların enerjisini dağıtır ve çatlak ilerlemesini engelleyici etki gösterir (Kelly ve Denry, 2008).

'Düşük isılarda bozulma' (low temperature degradation) fenomeninin ilk defa 1981 yılında tanımlanmıştır. Bu fenomen, zirkonyanın kendi yapısında var olan ve düşük ısılarda $\left(150-400^{\circ} \mathrm{C}\right)$ özellikle suyun varlığında zirkonya kristallerinin spontan olarak tetragonal fazdan daha zayıf olan monoklinik faza geçmesi ile yapının fiziksel özelliklerini zayıflatmasına sebep olan bir durumdur (AlAmleh ve arkadaşları, 2010).

2009 yılında Chevalier ve arkadaşları suyun ayrışması ile ortaya çıkan $\mathrm{OH}^{-}$iyonlarının değil de $\mathrm{O}^{2}$ - iyonlarının yapı içerisindeki oksijen boşluklarını doldurduklarını ve böylece LTD'nin ortaya çıkmasına neden olduğu öne sürülmüştür (Chevalier ve arkadaşları, 2009). Bu faz değişiminin meydana gelmesi için $200-300{ }^{\circ} \mathrm{C}^{\prime}$ lik kritik bir 1 sı aralığ 1 belirlenmiştir. Ortamda mevcut olan nem ise faz değişim miktarını artırmaktadır (Saldana ve arkadaşları, 2003).

Y-TZP içeren seramiklerde zamana bağlı olarak gelişen ve tetragonal fazın monoklinik faza geçişinin kontrolsüz bir şekilde artmasıyla kendini gösteren bir 'yaşlanma' olayı söz konusudur. Bu nedenle Y-TZP gibi polikristalin yapılar nemli ortamda zamanla yaşlanmaya eğilim gösterir ve buna bağlı olarak mekanik özelliklerinde bozulmalar görülür (Lughi ve Sergo, 2010)

\section{Zirkonyum Oksit Altyapı İle Üstyapı Seramiklerinin Bağlantı Mekanizması}

Zirkonya ve veneer seramik arasındaki bağlantıya etki eden faktörler bilinmesine rağmen, alt yapı ile üst yapı arasındaki bağlanma mekanizması henüz tam olarak bilinmemektedir (Fischer ve arkadaşları, 2009).

Tam seramik restorasyonlarda, alt yap1 ve üst yap1 seramiği arasındaki termal genleşme katsayısı uyumsuzluğunun olabildiğince az olması, alt yapı ve üst yapı seramiği arasında oluşan bağlantı başarısını etkilemektedir (Isgro ve arkadaşları, 2005). İyi bir bağlantı için, zirkonya ve veneer seramiğinin termal genleşme katsayılarının birbirine yakın olması gerekmektedir. Zirkonya, diğer seramiklere göre daha düşük termal genleşme katsayısına sahip olduğu için zirkonya ile aynı veya daha düşük termal genleşme katsayısına sahip özel üst yapı seramikleri geliştirilmiştir. Zirkonyum oksit seramiklerin termal genleşme katsayısı $\left(10.8 \times 10^{-6} \mathrm{~K}-1\right)$ zirkonyum oksit altyapılar için kullanılan veneer seramiklerin termal genleşme katsayısı $\left(9.1-9.7 \times 10^{-6}\right.$ K-1)'dan biraz daha büyüktür. Bu durum soğuma sırasında zirkonyanın daha fazla büzülmesine veneer seramiğe sıkıştırıcı kuvvet uygulamasına neden olur. Böylece metal destekli porselen sistemlerindeki gibi bir miktar sıkışmayla daha zayıf yapıdaki veneer seramiği zirkonyum oksit seramiğine bağlanır. Veneer seramiği ve zirkonyanın termal genleşme katsayısı arasındaki farkın $2.0 \times 10^{-6}{ }^{\circ} \mathrm{C}$ den fazla olması kendiliğinden veneer seramiğin delamine olmasına neden olabilmektedir. Yapılan çalışmalarda, 0.75-1.7x 10-6 ${ }^{\circ} \mathrm{C}$ aralığındaki katsayı farkının bağlanma dayanımına etki etmeyeceği bildirilmiştir (Saito A ve arkadaşları, 2007.

Y-TZP zirkonya alt yapı ile veneer seramik arasında, cam fazdaki iyon alışverişinin ve homojen yapının kimyasal bağlantı sağladığını belirten çalışmalar mevcuttur (Hegenbarth ve arkadaşları, 2007; Tholey ve arkadaşları, 2010). Ancak Kwon ve arkadaşları, zirkonya ve veneer seramik arasındaki bağlanmayı inceledikleri çalışmalarında, sinterlemeden sonra, zirkonya yüzeyindeki oksijen bileşimlerinin $\% 11.3$ 'ten $\% 21.3$ 'e yükseldiğini, partikül büyüklüğünün ise yaklaşık $0.2 \mu \mathrm{m}$ 'den $1 \mu \mathrm{m}$ 'ye çıtığını, zirkonya veneer seramik ara yüzünde mikropörözitelerin oluştuğunu, zirkonya-veneer seramik ara yüzünde elementlerin difüzyonunun veya migrasyonunun olmadığını gözlemişlerdir (Kwon ve arkadaşları, 2009). Zirkonya ile veneer seramik arasındaki bağlanmanın kimyasal değil mekanik olduğunu ve mikropörözitelerin bu bağlanmada ana faktör olabileceğini bildirmişlerdir.

Kimyasal bağlanma dayanımı, yüzey pürüzlülüğü ile sağlanan mekanik kilitlenme, ara yüzeydeki defektlerin tipi ve konsantrasyonu, 1slatma özelliği ve zirkonyaveneer seramik arasındaki termal genleşme katsayısının farklılığından dolayı veneer seramiğin sıkıştırma kuvvetinin 
derecesi bağlanma dayanımını etkileyen faktörler arasındadır (De Jager ve arkadaşları, 2005). Bu yüzden veneer seramik ile alt yapı arasındaki yeterli bağlanma dayanımı zirkonya restorasyonların uzun dönem klinik başarısı için bir endişe nedeni olmuştur.

\section{Zirkonya Alt Yapılı Sabit Protetik Restorasyonlarda Alt Yapı ve Üst Yapı Arasında Oluşan Başarısızlık Nedenleri, Bağlantıyı Arttırıcı İşlemler ve İlgili Çalışmalar}

Zirkonya alt yapılı sabit protetik restorasyonlar ile ilgili in vivo yapılan çalışmalarda en çok meydana gelen başarısızlık alt yapıdan veneer seramiğinin tabakalar halinde ayrılması yani delaminasyonudur (Fischer ve arkadaşları, 2009). Üstyapı materyalinde kırılmaların önlenmesi için zirkonya ve veneer seramiği arasındaki bağlanma direncinin yüksek veya üstyap1 materyalinin çiğneme streslerine yeterli derecede dayanıklı olması gerekmektedir (Aboushelib ve arkadaşları, 2005).

Zirkonya alt yap 11 sabit protetik restorasyonlar da, alt yap1 materyaliyle veneer seramiği arasındaki bağlantı direncini etkileyen faktörler; altyapıya uygulanan yüzey işlemleri, uygunsuz termal genleşme katsayısının sebep olduğu rezidüel stresler, altyapı ile üstyap1 ara yüzünde yapısal kusurlar ve çatlakların varlığı, zirkonyum oksit kristallerinin 1sıl etkilere veya stres yüklemelerine bağlı olarak faz dönüşümü gerçekleştirmesi, yüzeyin 1slanabilirliği, veneer seramiğin uygulanma tekniği, firınlanma sayıs1, üst yap1 seramiğinin hacimsel büzülmesi ve uygun olmayan soğutma oranları olarak sınıflandırılabilir (Aboushelib ve arkadaşları, 2006). Bu tip faktörler altyap 1 ve veneer seramiği arasındaki bağlantı direncinde ve dolayısıyla restorasyonun başarısında önemli rol oynamaktadır.

Zirkonya alt yapılı sabit protetik restorasyonlar da alt yapılar yüzeyine uygulanan bağlantıyı arttırmak için yapılan araştırmalarda mekanik ve kimyasal olmak üzere birçok yöntem kullanılmıştır: (Guazzato ve arkadaşları, 2005; Casucci ve arkadaşları, 2010). Bunlar; aluminum oksit ile kumlama, liner uygulaması, düşük grenli frezler yardımıyla yüzey pürüzlendirilmesi, plazma sprey uygulama, hidroflorik asit gibi asitlerin seramik yüzeyine uygulanması, silan uygulaması, lazer ışınlarının uygulanması ve bunların kombinasyonudur.

Rutin pürüzlendirme işlemi için uygulanan kumlama yöntemi ile artıklar ve oksitler yüzeyden uzaklaştırılarak mekanik bağlantıya elverişli temiz ve pürüzlü bir yüzey elde
edilir(Nakamura ve arkadaşları, 2004).Zirkonyumaltyapının 50-250 $\mu$ m'lik $\mathrm{Al}_{2} \mathrm{O} 3$ tozlarının 4-6 atmosfer basınçla 10 mm uzak mesafeden püskürtülmesi şeklinde yapılmaktadır (Fischer ve arkadaşları, 2007). Kumlama işlemi sırasında zirkonyum yüzeyinde çatlaklar oluşabilmekte ve lokal olarak yüzeyin tetragonal fazdan monoklinik $(\mathrm{t}-\mathrm{m})$ faza dönüşmesine neden olarak, restorasyonun klinik ömrünü olumsuz etkileyebilmektedir (Chintapalli RK ve arkadaşları, 2013). Bazı araştırmacılar, kumlamanın zirkonya ve veneer arasında bağlantıyı arttırdığını (Teng $\mathrm{J}$ ve arkadaşları, 2012; Liu D ve arkadaşları, 2013; Kim HJ ve arkadaşları, 2011; Nakamura T ve arkadaşları, 2009) ifade ederken bazı araştırmacılar ise bağlantı kuvvetini etkilemediğini bildirmişlerdir (Harding AB ve arkadaşları, 2012; Fischer J ve arkadaşları 2008; Ban S ve arkadaşları; 2013). Fischer ve arkadaşları, yaptıkları çalışmada, kumlamanın zirkonyanın yüzey pürüzlülüğünü arttırdığını, zirkonya ve seramik arasındaki bağlantıyı etkilemediğini bildirmişlerdir (Fischer J ve arkadaşları, 2008). Nakamura ve arkadaşları üç farklı basınçta (0.2, 0.4 ve $0.6 \mathrm{MPa})$ kumlanan zirkonya alt yapı ile veneer seramik arasındaki bağlanma dayanımını inceledikleri çalışmanın sonucunda kumlama basıncı ile elde edilen pürüzlülüğün doğru orantılı olarak arttığını ancak bu farkın bağlanma kuvvetini etkilemediğini belirtmiştir (Nakamura T ve arkadaşları, 2009).

Asit ile pürüzlendirme, seramik yapısında bulunan cam matriks ve kristal çözülerek mikropöroziteler oluşturmaktadır. Polikristalin seramiklerden olan zirkonya hacimce $\% 15^{\prime}$ ten daha az silika ve küçük bir miktar cam faz içerdiğinden asit ile pürüzlendirmenin etkili ve uygun bir yöntem olmadığı düşünülmektedir (Liu D ve arkadaşları, 2013; Zarone F ve arkadaşları, 2006).

Casucci ve arkadaşlarının 2009 yılında, zirkonya diskler üzerinde çeşitli yüzey işlemlerinin yüzey pürüzlülüğüne etkisi araştırdıkları çalışmanın sonucunda yüzey işlemlerinin yüzey pürüzlülügünü anlamlı olarak etkilediği, deneysel sıcak asit solüsyonun uygulanma sürelerinden bağımsız olarak yüzey pürüzlülüğünü artırdığı bildirilmiştir (Casucci ve arkadaşları, 2009).

Nikzadjamnan ve arkadaşları 2017 yılında yaptıkları çalışmada zirkonyaya uygulanan üç farklı yüzey işleminin altyapı ve veneer bağlantısına etkisini araştırmışlardır. Alüminyum oksit ile kumlama, karbondioksit lazer uygulaması, Er:YAG lazer uygulaması ve yüzeye hiç işlem yapılmayan bir kontrol grubu olmak üzere dört grup oluşturulup zirkonya bloklar yüzey işlemini takiben veneer seramiği ile kaplanmıştır. Çalışmanın sonuçlarına 
bakıldığında alüminyum oksit ile kumlama $\mathrm{CO} 2$ ya da $\mathrm{Er}$ : YAG lazer ışınlarına kıyasla daha yüksek bir mikrotensil bağlanma dayanımı gösterirken en düşük sonuçlar kontrol grubunda bulunmuştur. Her iki lazer grubu arasındaki fark anlamlı bulunmamıştır. Mikroskobik olarak incelenen yüzey yapısında alüminyum oksit ile kumlanan grupta pürüzlülük lazer uygulanan gruplara oranla daha fazla bulunmuştur (Nikzadjamnan ve arkadaşları, 2017).

Altyap1 porseleni ile üstyap1 porseleni arasındaki stres bölgelerinin azaltılması ve ideal bağlantının sağlanabilmesi için altyapı minimal kalınlık değerlerinde üretilmeli, marjinal kenarlar kontrol edilmeli ve gerekli ise düzeltmeler yapılmalıdır. Sinterizasyon işlemi sonrasında altyap1 separasyon diskleri ile separe edilmemelidir, böylece restorasyonun dayanıklılığını olumsuz etkileyecek kırık ve çatlak oluşumu engellenmiş olacaktır. Altyapı, artıklardan arındırılıp temizlendikten sonra herhangi bir temastan kaçınılmalıdır. Hazırlık işlemleri tamamlandıktan sonra altyapının renklendirilmesi amaciyla özel astar maddesi kullanılabilir. Bu materyal, zirkonya ile üst yap1 porselenin bağlantı direncini güçlendirmemekte fakat kırılmanın tipini etkilemektedir (Aboushelib MN ve arkadaşları, 2006).

Zirkonya ve veneer seramiği arasındaki bağlantı, veneer seramiğin uygulanma tekniğinden etkilenmektedir. Presleme tekniği ile yapılan veneer seramiklerinin, gerilme streslerine karşı dayanıklılıklarının fazla olması çatlak oluşumu oranını azaltmaktadır. Aboushelib ve arkadaşları, 2008 yılında presleme ve tabakalama yönteminin ayn restorasyonda beraber uyguladıkları (double veneer tekniği) bir çalışma yapmışlardır. Çalışmanın sonucuna göre double veneer tekniğinin zirkonya alt yapıların bağlantı dayanımını azaltmadığı gibi preslenebilir ve tabakalama yöntemlerinin avantajlarını birleştirdiğini bildirmişlerdir. $\mathrm{Bu}$ yöntem, preslenebilir seramikle yüksek bağlantı ve kaliteli bir ara yüzey; tabakalama yöntemiyle de daha iyi bir estetik elde edilmesini mümkün kılmaktadır (Aboushelib ve arkadaşları, 2008).

Zirkonya altyapılı seramik restorasyonlarda görülen chipping, delaminasyon gibi başarısızlıkların önüne geçebilmek için ortaya çıkarılan diğer bir yöntem de $\mathrm{CAD} / \mathrm{CAM}$ üretimli veneer porselen olmuştur. $\mathrm{CAD} /$ CAM üretiminin veneerin mekanik özelliklerini artırdığ 1 ileri sürülmektedir. $\mathrm{CAD} / \mathrm{CAM}$ üretimli veneerlerde tabakalama yöntemine göre daha az hata bulunmaktadır. Bunun iki önemli nedeni vardır: bloklar endüstriyel olarak üretilir ve materyal daha az defekt içerir. İkinci olarak da veneerin manuel üretiminin kaçınılmaz olarak hatalar oluşmasına neden olmasıdır (Schmitter M ve arkadaşları, 2014). Schmitter ve arkadaşlarının CAD/CAM üretimli ve tabakalama yöntemini karşılaştırdığı bir çalışmada $\mathrm{CAD} / \mathrm{CAM}$ üretimli veneerlerin yaşlandırma işlemine, tabakalanan veneerlere göre daha az duyarlı olduğunu göstermiştir (Schmitter M ve arkadaşları, 2013). Beuer ve arkadaşlarını yapmış oldukları çalışmada, CAD/CAM üretimli yüksek dayanımlı veneer porselenle venerlenmiş zirkonya alt yapıların kırılma dayanımlarını, tabakalama veya presleme yöntemi ile venerlenmiş zirkonya alt yapılarla karşılaştırmışlardır. CAD/CAM üretimli zirkonya altyapılı restorasyonların kırılma dayanımı ve uzun dönemde chipping görülme riski açısından geleneksel venerlemeye göre daha iyi sonuçlar verdiği bildirilmiştir (Beuer F ve arkadaşları, 2009).

Zirkonya-veneer seramik arasındaki bağlantının firınlama sonrası, soğuma hızından da etkilendiği bildirilmiştir. Göstemeyer ve arkadaşlarının 2010'da yaptıkları bir çalışmanın sonucunda zirkonya ve veneer arasındaki bağlantı direnci yavaş soğutma hızında düştüğü ve bu durumun yavaş soğutma hızının zirkonya - veneer ara yüzeyinde delaminasyon riskini artırdığını göstermiştir (Göstemeyer ve arkadaşları, 2010). Almeida ve arkadaşlarının 2013 yılında yapmış oldukları çalışmanın sonucunda, hızlı soğutma işlemi diğer soğutma tekniklerine göre anlamlı olarak daha yüksek bağlanma değerleri göstermiştir. Yavaş soğutma makaslama bağlantı dayanımı değerini düşürmüştür. Yavaş soğutmanın veneer seramiğin zirkonyaya olan bağlantısını azalttığı söylenebilir (Almeida ve arkadaşları, 2013).

Restorasyonlarda ideal renk, estetik ve formun sağlanabilmesiiçinbirçokfırınlamaişlemigerekebilmektedir. $\mathrm{Bu}$ işlemin zirkonya - veneer seramik bağlantısı üzerindeki etkisini inceleyen çalışmalarda firınlama sayısının bağlantı direncini anlamlı olarak etkilediği söylemişlerdir. Tabakalama tekniği ile veneer uygulamada, firınlama sayısının da bağlantıyı etkilediği düşünülmektedir; 3 ile 5 firınlama arasının bağlanma dayanımı arttırdığı (Trindade FZ ve arkadaşları, 2013), 6 firınlamadan sonra ise bağlantı kuvvetinin azaldığı bildirilmiştir (Zeighami ve arkadaşları, 2013). Fırınlama sayısındaki artış ile zirkonya - veneer seramik arasındaki bağlantının azalmasına neden olduğu için, fırınlama sayısının minimum oılması önerilmektedir (Zeighami ve arkadaşları, 2013). 


\section{SONUÇ}

Tüm bu çalışmalar ışığında alt yapı ve üst yapı bağlantısı; alt yapı yüzey bitiminden, soğutulma paterninden, viskoziteden, termal genleşme katsayısı uyumsuzluğundan, uygunsuz alt yap1 dizaynından, iki materyal arası 1slatabilirlikten, firınlanma sayısından, veneer porseleninin hacimsel büzülme davranışından, veneer seramiğin uygulanma tekniğinden etkilenmektedir. İyi bir bağlantının sağlanabilmesi için alt ve üst yapıların mekanik özelliklerinin birbirleri ile uyumlu olması gerekmektedir. Ara yüzdeki bağlantıya etki eden bu faktörler bilinmesine rağmen alt yapı ile üst yapı arasındaki bağlantı halen net bir şekilde açıklanamamıştır ancak iki materyal arasındaki mekanik kilitlenme mutlaka gereklidir. Zirkonya alt yapıya uygulanan farklı yüzey işlemlerinin, zirkonya-veneer seramik arasındaki bağlanma dayanımına etkileri konusunda kesin bir karara varabilmek için daha fazla çalışmanın yapılması gerekmektedir.

\section{KAYNAKLAR}

1. Aboushelib MN, Jager N, Kleverlaan CJ, Feilzer AJ. Microtensile bond strength of different components of core veneered all-ceramic restorations. Dent Mater. 2005; 21(10), 984-91.

2. Aboushelib MN, Kleverlaan CJ, Feilzer AJ. Microtensile bond strength of different components of core veneered allceramic restorations. Part II: Zirconia veneering ceramics. Dent Mater. 2006; 22(9), 857-63.

3. Aboushelib MN, Kleverlaan CJ, Feilzer AJ. Microtensile bond strenght of different components of core veneered all - ceramic restorations. Part 3: double veneer technique. J Prosthodont. 2008;17:9-13.

4. Al-Amleh B, Lyons K, Swain M. Clinical trials in zirconia: a systematic review. J Oral Rehabil. 2010; 37:641 - 652 .

5. Almeida AA, Longhini D, Domingues NB, Santos C, Adabo GL. Effects of extreme cooling methods on mechanical properties and shear bond strength of bilayered porcelain/3YTZP specimens J Dent. 2013; 41: 356-62.

6. Ban S, Sakakibara T, Yoshihara K, Takeuchi M, Kawai T, Murakami H, Kono H. Surface properties of dental zirconia after clinical grinding and polishing. Key Eng Mater. 2013; 24:501-506.

7. Beuer F, Schweiger J, Eichberger M, Kappert HF, Gernet W, Edelhoff D. High - strength CAD/CAM fabricated veneering material sintered to zirconia copings - a new fabrication mode for all ceramic restorations. Dent Mater. 2009; 25(1):121-8.

8. Blatz MB, Sadan A, Martin J, Lang B. In vitro evaluation of shear bond strengths of resin to densely-sintered high-purity zirconium-oxide ceramic after long-term storage and thermal cycling. J Prosthet Dent. 2004; 91(4):356-62.

9. Casucci A, Mazzitelli C, Monticelli F, Toledano M, Osorio R, Osorio E, Papacchini F, Ferrari M. Morphological analysis of three zirconium oxide ceramics: Effect of surface treatments. Dent Mater. 2010;26(8):751-60.

10. Casucci A, Osorio E, Osorio R, Monticelli F, Toledano M, Mazzitelli C, Ferrari M. Influence of different surface treatments on surface zirconia frameworks. J Dent. 2009;37(11):891-7.

11. Chevalier J, Gremillardw L. The Tetragonal-Monoclinic Transformation in Zirconia: Lessons Learned and Future Trends. J Am Ceram Soc. 2009; 92 [9] 1901-1920.

12. Chintapalli RK, Marro FG, Jimenez-Pique E, Anglada M. Phase transformation and subsurface damage in 3Y-TZP after sandblasting. Dent Mater. 2013; 29:566-572.

13. De Jager N, Pallav P, Feilzer AJ. The influence of design parameters on the FEA-determined stress distribution in CAD-CAM produced all-ceramic dental crowns. Dent Mater. 2005; 21: 242-51.

14. Denry I, Kelly R. State of the art of zirconia for dental applications. Dent Mater. 2008; 24(3):299 - 307.

15. Fischer J, Grohmann P, Stawarczyk B. Effect of zirconia surface treatments on the shear strength of zirconia/veneering ceramic composites. Dent Mater. J 2008; 27:448-454.

16. Fischer J, Stawarczyk B. Compatibility of machined CeTZP/A12O3 nanocomposite and a veneering ceramic. Dent Mater. 2007; 23:1500-5.

17. Fischer J, Zbaren C, Stawarczyk B, et al. The effect of thermal cycling on metalceramic bond strength. J Dent. 2009; 37: 549-553.

18. Göstemeyer G, Jendras M, Dittmer MP, Bach FW, Stiesch $\mathrm{M}$, Kohorst P. Influence of cooling rate on zirconia veneer interfacial adhesion. Acta Biomater. 2010; 6: 4532-8.

19. Guazzato M, Quach L, Albakry M, Swain MV. Influence of surface and heat treatments on the flexural strength of Y-TZP dental ceramic. J Dent. 2005; 33(1): 9-18.

20. Harding AB, Norling BK, Teixeira EC. The effect of surface treatment of the interfacial surface on fatigue-related microtensile bond strength of milled zirconia to veneering porcelain. J Prosthodont. 2012; 21:346-352.

21. Hegenbarth EA. Estetik ve zirkonyum dioksit çelişki mi? Quintessence Int . 2007;1: 53-66.

22. Isgro G, Kleverlaan CJ, Wang H, Feilzer AJ. The Influence of Multiple Firing on Thermal Contraction of Ceramic Materials Used for the Fabrication of Layered All-Ceramic Dental Restorations. Dent Mater. 2005; 21: 557-64.

23. Kelly J.R. Dental ceramics: current thinking and trends. Dent Clin North Am. 2004; 48: 513-530.

24. Kim HJ, Lim HP, Park YJ, Vang MS. Effect of zirconia surface treatments on the shear bond strength of veneering ceramic. J Prosthet Dent. 2011; 105:315-322.

25. Kwon JE. Lee SH, Lim HN, Kim HS. Bonding characteristics between zirconia core and veneering porcelain. Dent Mater. 2009; 25: 42 .

26. Liu D, Matinlinna JP, Tsoi JK, Pow EH, Miyazaki T, Shibata Y. A new modified laser pretreatment for porcelain zirconia bonding. Dent Mater. 2013; 29:559-565.

27. Lughi V, Sergo V. Low temperature degradationaging of zirconia: A critical review of the relevant aspects in dentistry. Dent Mater. 2010; 26(8):807-820. 
28. Microtensile bond strength of different components of core veneered all-ceramic restorations. Part 3: double veneer technique. J Prosthodont. 2008; 17(1):9-13.

29. Munoz-Saldana J, Balmori-Ramirez H, Jaramillo-Vigueras D, Iga T, Schneider GA. Mechanical properties and low temperature aging of tetragonal zirconia polycrystals pressed by hot isostatic pressing. J Mater Res. 2003; 18: 2415e26.

30. Nakamura S, Yoshida K, Kamada K, Atsuta M. Bonding between resin luting cement and glass infiltrated aluminareinforced ceramics with silane coupling agent. J Oral Rehabil. 2004; 31(8):785-9.

31. Nakamura T, Wakabayashi K, Zaima C, Nishida H, Kinuta $\mathrm{S}$, Yatani $\mathrm{H}$. Tensile bond strength between tooth-colored porcelain and sandblasted zirconia framework. J Prosthodont Res. 2009; 53:116-119.

32. Nikzadjamnani S, Zarrati S, Rostamzadeh M. Microtensile Bond Strength Between Zirconia Core and Veneering Porcelain After Different Surface Treatments. J Dent. 2017; 14(6): 303-312.

33. Raigrodski AJ. Contemporary materials and technologies for all-ceramic fixed partial dentures: a review of the literature. J Prosthet Dent. 2004; 92(6), 557-62.

34. Saito A, Komine F, Blatz MB, Matsumura H. A comparison of bond strength of layered veneering porcelains to zirconia and metal. J Prosthet Dent. 2010; 104:247-257.

35. Schmitter M, Mueller D, Rues S. In vitro chipping behaviour of all ceramic crowns with a zirconia framework and feldspathic veneering: comprasion of $\mathrm{CAD} / \mathrm{CAM}$ produced veneer with manually layered veneer. J Oral Rehabil. 2013; 40: 519-25.

36. Schmitter M, Schweiger M, Mueller D, Rues S. Effect on in vitro fracture resistance of the technique used to attach lithium disilicate ceramic veneer to zirconia frameworks. Dent Mater. 2014; 30: 122-30.

37. Silva N, Sailer I, Zhang Y, Coelho PG, Guess PC, Zembic A, Kohal RJ. Performance of zirconia for dental healthcare. Materials. 2010; 3: 863-896.

38. Teng J, Wang H, Liao Y, Liang X. Evaluation of a conditioning method to improve core-veneer bond strength of zirconia restorations. J Prosthet Dent. 2012; 107:380 - 387.

39. Tholey MJ, Berthold C, Swain MV, Thiel N. XRD2 microdiffraction analysis of the interface between Y-TZP and veneering porcelain: role of application methods. Dent Mater. 2010;26(6):545-52.

40. Trindade FZ, Amaral M, Melo RM, Bottino MA, Valandro LF. Zirconia-porcelain bonding: effect of multiple firings on microtensile bond strength. J Adhes Dent. 2013; 15: 467-472.

41. Zarone F, Sorrentino R, Vaccaro F, Traini T, Russo S, Ferrari M. Acid etching surface treatment of feldspathic, alumina and zirconia ceramics: a micromorphological SEM analysis. Int Dent South Africa. 2006; 8:50-56.

42. Zeighami S, Mahgoli H, Farid F, Azari A. The effect of multiple firings on microtensile bond strength of core-veneer zirconia-based all-ceramic restorations. J Prosthodont. 2013; 22: 49-53. 